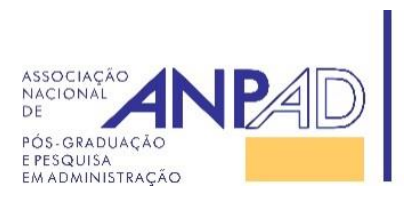
Disponível em
http://www.anpad.org.br/rac
RAC, Rio de Janeiro, v. 21, n. 1, art. 4, pp. 62-83, Jan./Fev. 2017

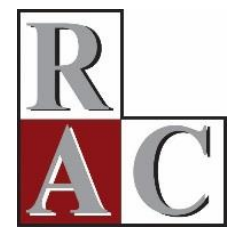

\title{
Análise do Perfil dos Acadêmicos e de suas Publicações Científicas em Administração
}

An Analysis of Academics and their Scientific Publications in the Field of Management

Takeyoshi Imasato ${ }^{1}$ Marcelo Scherer Perlin ${ }^{1}$

Denis Borenstein ${ }^{1}$

Universidade Federal do Rio Grande do Sul ${ }^{1}$ 


\title{
Resumo
}

A produção da ciência tem sido foco de diversas discussões, particularmente no que se refere à produtividade científica. Este artigo tem como objetivo analisar o perfil de pesquisadores doutores que atuam na área de Administração no Brasil e as suas respectivas publicações científicas, de modo a identificar fatores que expliquem esse aspecto da produtividade científica. Utilizando estatística descritiva e modelos estatísticos, com base em dados provenientes de 1976 docentes registrados na Plataforma Lattes, a pesquisa identificou fatores ligados à formação e experiência que influem na produtividade científica dos acadêmicos em Administração. Os resultados da pesquisa também indicam que houve importantes modificações nos padrões de formação acadêmica e de produtividade no país. Considerando a centralidade do tema da produtividade científica, o trabalho sugere novas pesquisas para que se ampliem as discussões sobre os rumos da produção intelectual e da pós-graduação em Administração no Brasil.

Palavras-chave: perfil de pesquisador; publicação científica; Plataforma Lattes; pesquisa em administração.

\begin{abstract}
Scientific production has been the focus of many discussions, particularly regarding the issue of scientific productivity. This study analyzes the profile and publications of academics (PhDs) working in the field of management in Brazil and their respective scientific publications, in order to identify the factors that explain this particular aspect of scientific productivity. Using descriptive statistics and statistical models based on data about 1976 researchers registered on the Brazilian Lattes database which compiles Brazilian academic researchers' curriculum vitaes, the study identified factors related to academic education and experience that have an impact on academics' scientific productivity in Management. Research results also indicate that important changes in the patterns of academic education and productivity are taking place in Brazil. Considering the centrality of scientific productivity, the paper suggests new studies to increase discourse regarding the future path of intellectual production and graduate management programs in Brazil.
\end{abstract}

Key words: researcher profile; scientific publication; Lattes Platform; management research. 


\section{Introdução}

As instituições acadêmicas têm sido foco de debates e reflexões ao longo das últimas décadas, tanto no âmbito nacional quanto internacionalmente. Há questionamentos em relação aos seus fundamentos institucionais, o que tem sido observado na comunidade acadêmica de diferentes áreas de atuação e em diferentes países, não ficando restrito a algum campo de conhecimento em particular (Domingues, 2014). Nesses termos, existe uma crescente preocupação com o modo pelo qual a ciência vem sendo praticada e organizada (Gad-el-Hak, 2004; McGrail, Rickard, \& Jones, 2006).

Uma das áreas acadêmicas de atuação, mais discutidas em décadas recentes está relacionada com a publicação científica. Os questionamentos e os problemas apontados ocorrem sob diferentes perspectivas e se manifestam de distintas formas. Internacionalmente, o lema publique ou pereça (publish or perish) tem sido apontado como um elemento institucional cada vez mais presente e marcante no contexto acadêmico. Há uma constatação de que é crescente a exigência de publicação de artigos em periódicos científicos considerados como os de maior impacto em diversos países (McGrail, et al., 2006; Parker, Guthrie, \& Gray, 1998; Rond \& Miller, 2005; Van Dalen \& Henkens, 2012).

Esse tema tem sido tópico de intensos debates em diferentes academias, como nos Estados Unidos, Reino Unido e Austrália (Adler \& Harzing, 2009; Cooper \& Poletti, 2011; Hoepner \& Unerman, 2012). Embora esta discussão tenha tomado um tom mais crítico no Brasil, por meio da discussão do produtivismo (e.g., Alcadipani, 2011; Freitas, 2011; Godoi \& Xavier, 2012), é inegável que a produção científica é um elemento fundamental para a avaliação de projetos de pesquisa, da qualidade de programas de pós-graduação ou para a avaliação de desempenho acadêmico. Assumimos, portanto, que produtividade é um relevante aspecto para a vida de um pesquisador no Brasil, inclusive em Administração.

Vários autores discutem indicativos de que elementos atrelados à produtividade possam estar correlacionados com a própria dinâmica da formação e de atuação no campo acadêmico, influenciando, assim, no perfil dos pesquisadores (Anderson, Ronning, De Vries, \& Martinson, 2007; Horta \& Santos, 2016; Miller, Taylor, \& Bedeian, 2011). No Plano Nacional de Pós-Graduação 2011-2020, publicado pela Coordenação de Aperfeiçoamento de Pessoal de Nível Superior (CAPES) em 2010, houve a indicação de que as áreas de avaliação "deverão ter em mente o tipo de profissional ou de pesquisador que se deseja formar, considerando-se a diversidade da sociedade do conhecimento e das suas demandas" (CAPES, 2010, p. 129). Apesar de haver estudos que destaquem informações sobre a formação, emprego e características demográficas dos doutores no Brasil (Centro de Gestão e Estudos Estratégicos [CGEE], 2010), há poucas análises específicas que englobam a trajetória e o perfil dos pesquisadores atuando no Brasil em Administração e suas publicações (e.g., Pegino, 2014).

Em particular, não há análises que correlacionam o perfil de pesquisadores e a produção científica na área de Administração no Brasil, tendo como referência uma base de dados extensa dos acadêmicos doutores atuantes nesse campo. Utilizando como base os doutores atuando em Administração, a presente pesquisa foca a seguinte questão de pesquisa: há fatores de perfil dos acadêmicos que explicam as diferenças de produtividade científica entre os pesquisadores na área de Administração? A eventual identificação desses fatores pode ajudar a esclarecer a relação entre o perfil dos acadêmicos e suas respectivas publicações científicas. Explorar os dados relativos a esse grupo de acadêmicos também pode auxiliar na reflexão das mudanças institucionais em curso, particularmente em relação à publicação científica em periódicos, podendo qualificar, desse modo, as discussões relacionadas à produtividade na área de Administração.

O objetivo deste artigo é o de analisar o perfil de acadêmicos doutores que atuam na área de Administração no Brasil e as suas respectivas publicações científicas. Utilizando modelos estatísticos, serão analisados também os fatores que explicam a produtividade científica entre os diferentes pesquisadores, tendo como foco os artigos publicados em periódicos científicos indexados. Essa pesquisa busca compreender como a produção acadêmica tem se desenvolvido nas últimas décadas, analisando fatores (tais como formação e experiência) que influem na produtividade dos acadêmicos em 
Administração. Busca-se, assim, analisar, de forma rigorosa, as discussões e mitos que vêm sendo apresentados em relação à publicação científica em Administração no Brasil, tendo como base os currículos dos doutores registrados na Plataforma Lattes.

\section{Publicações Científicas, Produtividade e Perfil de Acadêmicos}

A publicação é parte integrante do processo de produção de conhecimentos científicos na academia. Artigos em periódicos, livros, capítulos de livros, anais de congressos, resumos, teses, dissertações e monografias, entre outros meios de divulgação, são elementos de vital importância no sistema de comunicação da ciência (Domingues, 2014).

A despeito da variedade de meios de comunicação, a forma de publicação científica que tem recebido maior atenção nas últimas décadas é o artigo publicado em periódicos indexados com revisão pelos pares, ou peer review (McGrail et al., 2006; Parker et al., 1998; Starbuck, 2005; Van Dalen \& Henkens, 2012). Em termos gerais, o foco em artigos publicados em periódicos indexados ganhou essa proeminência institucional por proporcionar a execução dos seguintes processos: (a) o registro da quantidade de citações realizadas que fazem referência a um artigo em particular, que pode indicar a recepção e impacto do trabalho publicado; (b) o cálculo do fator de impacto da revista, realizado com base na extração da média de citações dos artigos publicados em um periódico específico, dentro de um período determinado de tempo; e (c) a estratificação das publicações, particularmente por meio de listas (ou rankings), que permite a classificação das revistas de acordo com o fator de impacto, a percepção de qualidade ou o prestígio do periódico.

No âmbito internacional, o uso de artigos científicos como base para tomada de importantes decisões nas Universidades tem se intensificado. Avaliação de desempenho de acadêmicos, orientação do sistema de promoções, remuneração, aquisição de estabilidade (tenure) e acesso a recursos de pesquisa (Rond \& Miller, 2005; Starbuck, 2005; Van Dalen \& Henkens, 2012) são exemplos de decisões nas quais a publicação científica desempenha um papel relevante. Nesses termos, a publicação de artigos se tornou elemento-chave na avaliação da produtividade científica dos acadêmicos, tendo como suporte as métricas e rankings que foram associados a essa forma de produção acadêmica (Adler \& Harzing, 2009; Domingues, 2014; Horta \& Santos, 2016; Parker et al., 1998). Tal situação, mais particular ao contexto universitário dos Estados Unidos em um primeiro momento, passou a ser disseminada e incorporada em diversos outros países nas últimas três décadas, como na África do Sul, Austrália, Brasil, China, França e Reino Unido.

Em paralelo ao crescente foco na publicação de artigos em periódicos científicos indexados no âmbito acadêmico, a análise da relação do perfil individual dos acadêmicos e de suas respectivas produtividades tem se consolidado como uma linha de investigação (Horta \& Santos, 2016; Ross et al., 2014). Apesar de os primeiros trabalhos nessa linha remontarem ao início do século XX (Lissoni, Mairesse, Montobbio, \& Pezzoni, 2011), a identificação de fatores específicos que possam explicar as diferenças nos desempenhos individuais em publicações passou a ser um tema de interesse, dada a sua relevância institucional no contexto universitário contemporâneo (Horta \& Santos, 2016; Van Dalen \& Henkens, 2012). Características individuais de acadêmicos como idade, gênero, instituição de origem, formação acadêmica, posição na carreira, produção passada, incentivos, entre outros, passaram a ser analisadas como possíveis variáveis explicativas da produtividade científica na literatura (Horta \& Santos, 2016; Lissoni et al., 2011; Rorstad \& Aksnes, 2015; Ross et al., 2014).

Apesar da inegável relevância da publicação de artigos em periódicos como parte do ofício acadêmico, o foco apenas nesse tipo de produção científica suscita discussões relacionadas à produtividade científica (Adler \& Harzing, 2009; Anderson et al., 2007; Domingues, 2014; Freitas, 2011). Um primeiro ponto de discussão é o resultado gerado pelo contexto de pressão institucional por publicações em periódicos indexados, traduzido tanto pelo lema publique ou pereça como no conceito de produtivismo. O crescente número de submissões de trabalhos em revistas, a proliferação de 
periódicos, o imperativo de avaliação da carreira de acadêmicos baseada na quantidade de publicações, o gradual abandono de outras formas de publicação e premiações por número de publicações são alguns dos aspectos observados na literatura sobre o predomínio de publicações em periódicos indexados (Alcadipani, 2011; Rond \& Miller, 2005; Van Dalen \& Henkens, 2012).

Outro ponto de discussão relevante é a estratificação da qualidade dos periódicos por meio de rankings. Existe um reconhecimento de que a existência dos sistemas de classificação influencia na definição de prioridades para fins de publicação, além de moldar a própria noção de qualidade (Adler \& Harzing, 2009; Parker et al., 1998). No Reino Unido, onde há um sistema de classificação chamado $A B S$ Journal Quality Guide, e na Austrália, país que criou o Excellence in Research for Australia (ERA), há trabalhos avaliando os efeitos dessas listagens de estratificação nas publicações científicas (e.g., Rafols, Leydesdorff, O’Hare, Nightingale, \& Stirling, 2012). Críticas são feitas a ambos os sistemas de estratificação pela idiossincrasia e imprecisão na classificação de revistas oriundas dessas listagens (e.g., Cooper \& Poletti, 2011; Hoepner \& Unerman, 2012), sugerindo a necessidade de cautela na avaliação da qualidade da produtividade científica centrada apenas nesse quesito (Adler \& Harzing, 2009; Rond \& Miller, 2005; Starbuck, 2005). No Brasil, o sistema de estratificação oficial utilizado é o Qualis, que classifica os estratos de qualidade com base na avaliação de comissões constituídas em cada uma das áreas de avaliação da CAPES. Desse modo, é provável que o Qualis possa apresentar os mesmos problemas e limitações apontados na literatura internacional.

A despeito dessas limitações, ressaltadas em diferentes esferas de discussão sobre produtividade científica, a análise do perfil de acadêmicos e das suas respectivas publicações é um tema relevante de pesquisa pouco explorado na área de Administração no Brasil. A análise elaborada por Pegino (2014) ajuda a ressaltar alguns dos elementos relacionados à produção em Administração. A pesquisa realizada pelo autor, restrita a dados da produção acadêmica dos bolsistas de produtividade do CNPq em Administração, destacou haver uma tendência de produtividade centrada mais na quantidade de publicações e que um pesquisador necessita de cerca de 10 anos, em média, para publicar um artigo em periódico indexado no Journal Citation Reports (JCR) com fator de impacto superior a 1.0. Esse levantamento indica a relevância de se explorar essa linha de investigação.

Em suma, mesmo sendo um tema de acalorados debates, informações sobre o perfil dos acadêmicos e da sua respectiva produtividade científica ainda são pouco conhecidas e estudadas, inclusive no campo de Administração. Há especificidades institucionais no Brasil que ainda não foram levantadas e que precisam ser reconhecidas. A partir da análise do perfil dos acadêmicos e de suas respectivas publicações científicas, há a possibilidade de se esclarecer se existe relação entre esses elementos, podendo adicionar novos aspectos às discussões existentes na literatura e qualificá-las. Este artigo tem como principal objetivo contribuir para esta discussão na literatura nacional.

\section{Metodologia de Pesquisa}

A presente pesquisa utilizou procedimentos metodológicos orientados para a análise de uma grande base de dados que foi construída, utilizando currículos da Plataforma Lattes, de modo a oferecer descrições, interpretações e algumas possíveis explicações do fenômeno estudado. Na primeira subseção deste capítulo, será apresentado o processo de construção dos dados utilizados e algumas estatísticas descritivas. O modelo estatístico empregado para realizar as análises será desenvolvido na segunda subseção.

\section{Dados utilizados}

Os dados utilizados para este artigo são originários exclusivamente da plataforma on-line de currículos, o Lattes. Essa plataforma é uma fonte confiável de dados, uma vez que a atualização das informações pelos usuários é indispensável para diversas atividades acadêmicas junto a instituições de fomento à pesquisa (ver Lane, 2010). O Lattes possibilita acesso a uma vasta fonte de informações, em 
geral atualizadas para a análise da produção científica, o que justifica o seu uso no presente artigo. Todos os dados utilizados no artigo foram acessados via utilização de um software proprietário que permitiu a exploração e tabulação dos dados do Lattes em larga escala.

Alguns detalhes a respeito da estrutura da plataforma são importantes para a análise. No momento em que um acadêmico cria um novo currículo Lattes, há a possibilidade de escolha de até cinco grandes áreas dentro do campo área de atuação, em que existem, para cada uma das cinco escolhas, três outros subníveis de especialidade. Por exemplo, um pesquisador pode escolher a grande área de ciências sociais aplicadas, área de comunicação, subárea de jornalismo e editoração e com especialidade em teoria e ética do jornalismo.

Para o caso específico de análise na área de Administração, o primeiro passo do artigo foi o de obter a lista de pesquisadores com doutorado. Em uma filtragem inicial dos currículos, foram selecionados os currículos dos pesquisadores que indicaram a sua grande área como Ciências Sociais Aplicadas, e Administração como área. Todas as subáreas e especialidades desses dois primeiros filtros foram incluídas. Para a área de Administração, as subáreas foram Administração de Empresas, Administração de Setores Específicos, Administração Pública e Ciências Contábeis. Tais subáreas fazem parte do perfil de cada um dos acadêmicos analisados.

Para fins desta pesquisa, a análise da produtividade científica ficou restrita a publicações em periódicos. Entendemos que o conceito de produtividade científica em si é mais abrangente (Adler \& Harzing, 2009; Domingues, 2014). Orientações de discentes, revisão de manuscritos acadêmicos, atividades de extensão e publicação de livros, entre outras atividades acadêmicas, também são quesitos de produtividade científica, mas que não possuem formas de mensuração ou estratificação consolidadas para eventuais análises estatísticas em uma base de dados massiva, como a construída neste trabalho. Entende-se a importância destes outros elementos de produção científica, porém, dentro de nossos objetivos, o uso dos mesmos não se demonstrou viável.

Um problema encontrado nesta filtragem inicial é que muitos dos currículos obtidos apresentavam um alto volume de publicações em periódicos não relacionados com a área de Administração no Qualis. Em outros casos, os periódicos constavam como sendo não cadastrados. Suspeita-se que a atuação do pesquisador na área de Administração não era predominante, o que nos leva a construir uma filtragem adicional para lidar com estes casos. Considerando que a tabela Qualis é particular a cada área de conhecimento, sendo definida pelos pares em um comitê organizado pela CAPES, o método escolhido foi utilizar a relação de periódicos listados no Qualis para a área de Administração como benchmarking. Foi utilizada como referência, nesta pesquisa, a tabela do ano base de 2014, utilizando-se os níveis de classificação de periódicos (A1, A2, B1, B2, B3, B4 e C) definidos nesse ano base. Como resultado, aqueles autores que não apresentavam mais de $50 \%$ de sua produção científica em periódicos registrados no Qualis da Administração e sem publicações com International Standard Serial Number (ISSN) foram excluídos da análise ${ }^{(1)}$.

Após essa última filtragem, a base de dados de publicações foi novamente organizada para contemplar apenas artigos em periódicos com registro de ISSN e publicados entre 1990 e $2014^{(2)}$. Todos os dados utilizados para as análises foram coletados em março de 2015. Os dados obtidos podem ser separados em duas partes, a primeira referente às informações dos pesquisadores, e a segunda, a respeito das informações das publicações. Para os dados dos pesquisadores, as seguintes informações foram coletadas: (a) Nome do pesquisador; (b) Área, subárea e especialidade; (c) Ano, duração e local do doutorado; (e) Endereço de correspondência; (f) Existência ou não de bolsa de produtividade em pesquisa do CNPQ. Para os dados das publicações, as seguintes informações foram acessadas: (a) Nome do pesquisador; (b) Nome do periódico; (c) Ano da publicação; (d) ISSN do periódico.

Outra fonte de dados utilizada é a originária do Scimago Journal \& Country Rank (SJR), tendo como base a listagem existente em agosto de 2015. Esta base de dados inclui o ISSN dos periódicos, seu respectivo SJR (fator de impacto), entre outras informações. Com os dados do ISSN das publicações, foi possível correlacionar as informações entre as publicações no Lattes e os fatores de impacto SJR dos periódicos. A Tabela 1 apresenta a análise descritiva dos dados obtidos junto à plataforma Lattes. 
Tabela 1

\section{Estatística Descritiva dos Dados}

\begin{tabular}{ll}
\hline Número de artigos & 42775 \\
Número de pesquisadores & 1976 \\
$\%$ Doutorado fora do Brasil & $12,56 \%$ \\
$\%$ Bolsa produtividade CNPq & $5,97 \%$ \\
Média tempo Doutorado (anos) & 3,957 \\
$\%$ de artigos com SJR & $12,66 \%$ \\
Média de fator de impacto (SJR) & 0,37 \\
Média de pontos Qualis por artigo & 45,51 \\
\hline
\end{tabular}

A primeira informação que se destaca na Tabela 1 é o volume dos dados. A base de dados inicial continha 5.073 pesquisadores e 66.558 publicações. Após a filtragem, 42.775 publicações foram mantidas. Destaca-se que o mesmo artigo pode ter sido contado mais de uma vez, caso dois ou mais coautores tenham sido contabilizados na amostra. Dentre os acadêmicos analisados, uma pequena parcela $(12,56 \%)$ realizou o seu doutorado fora do Brasil, enquanto uma parcela ainda menor $(5,97 \%)$ possui bolsa de produtividade em pesquisa do CNPq.

É interessante notar que poucos trabalhos publicados pelos respectivos pesquisadores são indexados pelo SJR, o que indica uma predominância de trabalhos nacionais na base de dados, uma vez que a quantidade de periódicos brasileiros da área de Administração indexados no SJR é pequena. Uma investigação nos dados mostra que aproximadamente $55 \%$ dos pesquisadores possuem pelo menos uma publicação em um periódico indexado no SJR. É interessante também notar que a média de pontos Qualis obtido por cada pesquisador é de 45,51 , cujo estrato mais próximo é o B2 (50 pontos). A média de fator de impacto encontrada também é baixa em termos relativos aos periódicos cadastrados no SJR.

\section{Modelo estatístico de análise}

Um dos objetivos do trabalho é o de identificar se há fatores de perfil que explicam as diferenças de produtividade científica entre os pesquisadores na área de Administração. Utilizando como base o trabalho de Rorstad e Aksnes (2015), o método escolhido foi o da estimação de um modelo econométrico linear, tendo diferentes proxies para explicar a produtividade científica dos pesquisadores (Rorstad \& Aksnes, 2015; Ross et al., 2014). O uso do modelo linear é justificado por sua fácil estimação e pela possiblidade de comparação dos resultados obtidos em relação à literatura.

Todavia, diferentemente do método de Rorstad e Aksnes (2015), que desenvolveram um modelo de regressão em que a taxa de publicação individual foi calculada em função do gênero, idade e posição acadêmica (dados existentes na base de dados da Noruega, o Current Research Information System in Norway), o modelo utilizado no presente estudo adaptou as variáveis de análise com base nos dados disponíveis no Lattes ${ }^{(3)}$. Quatro variáveis foram então definidas como explicativas para a produtividade científica em publicação em periódicos: (a) Anos desde o doutorado; (b) Duração do doutoramento; (c) Existência de bolsa de produtividade do CNPq e (d) Realização de Doutorado fora do país. A primeira variável explicativa, quantidade de anos desde o doutorado, é justificada pelo efeito relatado por Rorstad e Aksnes (2015) do tempo sobre a produtividade científica. Pesquisas anteriores mostram que a produtividade científica aumenta com o tempo, atinge um pico e tende a decrescer posteriormente. Esta não-linearidade do efeito é incorporada por meio da adição da variável nominada como anos desde o doutorado ao quadrado. A segunda variável, duração do doutoramento, testa a relação entre a duração do doutorado e a produtividade do pesquisador. Ela é uma variável possivelmente inédita e nunca testada, uma vez que não possui respaldo na literatura pesquisada. Esse teste é interessante, pois a duração do doutorado é uma informação anterior ao início do trabalho do pesquisador após o término 
do curso. Portanto, caso esta variável for significativa, o tempo do doutoramento pode servir como um elemento analítico em alguns casos.

A terceira variável explicativa, existência de bolsa de produtividade, busca analisar se aqueles pesquisadores com bolsa de produtividade concedida pelo CNPq possuem produção científica acima da média. Tal hipótese foi testada em outras áreas, tal como Enfermagem (Souto et al., 2012) e Educação Física (Leite et al., 2012). Apesar de problemas de causalidade de seleção, visto que os pesquisadores mais produtivos são geralmente aqueles escolhidos para ganhar esta bolsa, destaca-se a importância de verificar esse quesito na área de Administração, dado que o mecanismo de incentivo financeiro tem potencial de alavancar a produtividade científica em periódicos da área. A última variável explicativa, realização do doutorado fora do país, busca analisar se o doutoramento em instituições internacionais pode resultar em uma produtividade científica mais elevada dentro da área de Administração. Esse tipo de teste foi realizado na literatura, tendo resultados positivos (Ross et al., 2014).

A seguir apresenta-se o modelo:

$$
\operatorname{ProdAc}_{i}=\alpha_{i}+\beta_{1} \text { AnoDesdeDout }_{i}+\beta_{1} \text { AnoDesdeDout }_{i}^{2}+\beta_{2} \text { intDout }_{i}+\beta_{3} D_{-} \text {BolsaProd }_{i}+\beta_{4} D_{-} \text {DocFora }_{i}+\varepsilon_{i}
$$

Onde:

$\operatorname{prodAc}_{i}$

AnoDesdeDout $_{i}$ intDout $_{i}$

D_BolsaProd ${ }_{i}$

D_DocFora ${ }_{i}$
-> Proxy para produtividade de publicação científica do pesquisador $i$

-> ano desde o doutorado do pesquisador $i$

-> intervalo (duração) do doutorado do pesquisador $i$

-> dummy para bolsa de produtividade do pesquisador $i$

-> dummy para doutorado fora do Brasil do pesquisador $i$

Para a variável $\operatorname{prodAc}_{i}$, serão utilizadas quatro variáveis diferentes como proxies de produtividade científica:

. Média de pontos Qualis por autor;

- Número de artigos por ano, desde fim do doutorado;

. Média de SJR (definindo-se como SJR igual a zero para aqueles artigos sem fator de impacto);

- Percentagem de trabalhos publicados no SJR.

Destaca-se que a escolha das proxies leva em conta a quantidade e a qualidade das publicações. Para a qualidade, utilizam-se o Qualis, um critério nacional, e também o fator de impacto definido pelo SJR, que é um critério internacional. Apesar de o SJR não ser uma escala com igualdade de proporção, optamos por utilizar a média do SJR para cada pesquisador, visto que o cálculo de outras medidas de tendências, tal como moda e mediana, resultava em uma grande quantidade de valores iguais a zero. Tal efeito deve-se ao fato de que a grande maioria das publicações na base de dados era em periódicos não listados no SJR (veja Tabela 1). Isto inviabilizava as regressões da pesquisa, uma vez que a variável dependente não tinha variabilidade suficiente, prejudicando as conclusões obtidas nesta etapa estatística. Tendo como objetivo manter a robustez da pesquisa e evitar algum viés gerado pela exclusão dos pesquisadores com baixa produção em SJR, optamos por utilizar a média de SJR como o índice de qualidade das publicações de cada pesquisador, apesar de a mesma não ser, necessariamente, a escolha ideal. 


\section{Resultados}

A apresentação dos resultados foi dividida em três partes. Na primeira subseção, serão feitas as descrições do perfil dos pesquisadores. Na segunda subseção, serão analisadas as publicações científicas coletadas na pesquisa. Por fim, serão apresentados, na terceira parte, os resultados da análise dos fatores da produtividade científica dos pesquisadores.

\section{Sobre os pesquisadores}

O primeiro resultado apresentado é a distribuição dos pesquisadores da área de Administração entre as suas subáreas e especialidades. Os dados mostram que dentro das subáreas da Administração, uma grande proporção é de Administração de Empresas (52,52\%), seguida por Ciências Contábeis (18,29\%), Administração Pública (15,75\%) e Administração de Setores Específicos (13,44\%).

A Figura 1 apresenta a divisão de pesquisadores de acordo com a sua especialidade. Observando a figura, podemos notar que as áreas de Administração de Recursos Humanos e Administração Financeira são as que possuem o maior número de pesquisadores vinculados, seguido pela especialidade de Mercadologia (Marketing).

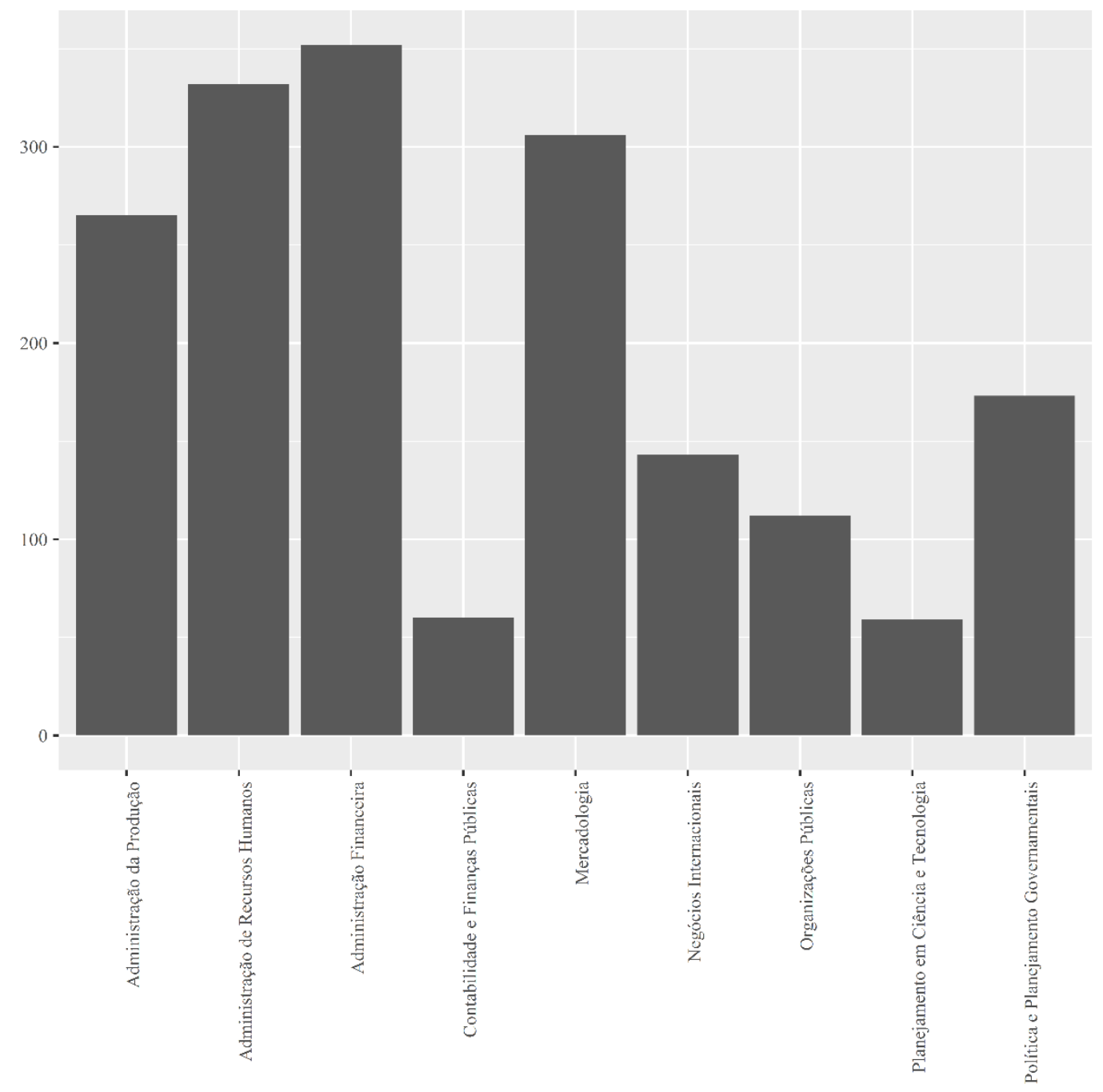

Figura 1. Quantidade de Pesquisadores por Especialidade 
Observa-se uma informação interessante quando se analisa o histograma do ano de doutoramento dos pesquisadores, apresentado na Figura 2. Existe uma tendência positiva para o número de doutores formados a cada ano. Em 1990, formaram-se oito doutores, enquanto que em 2014, formaram-se 159 novos pesquisadores, representando um crescimento de $1887 \%$ no período. Esta tendência acelerou significativamente a partir do ano de 2000.

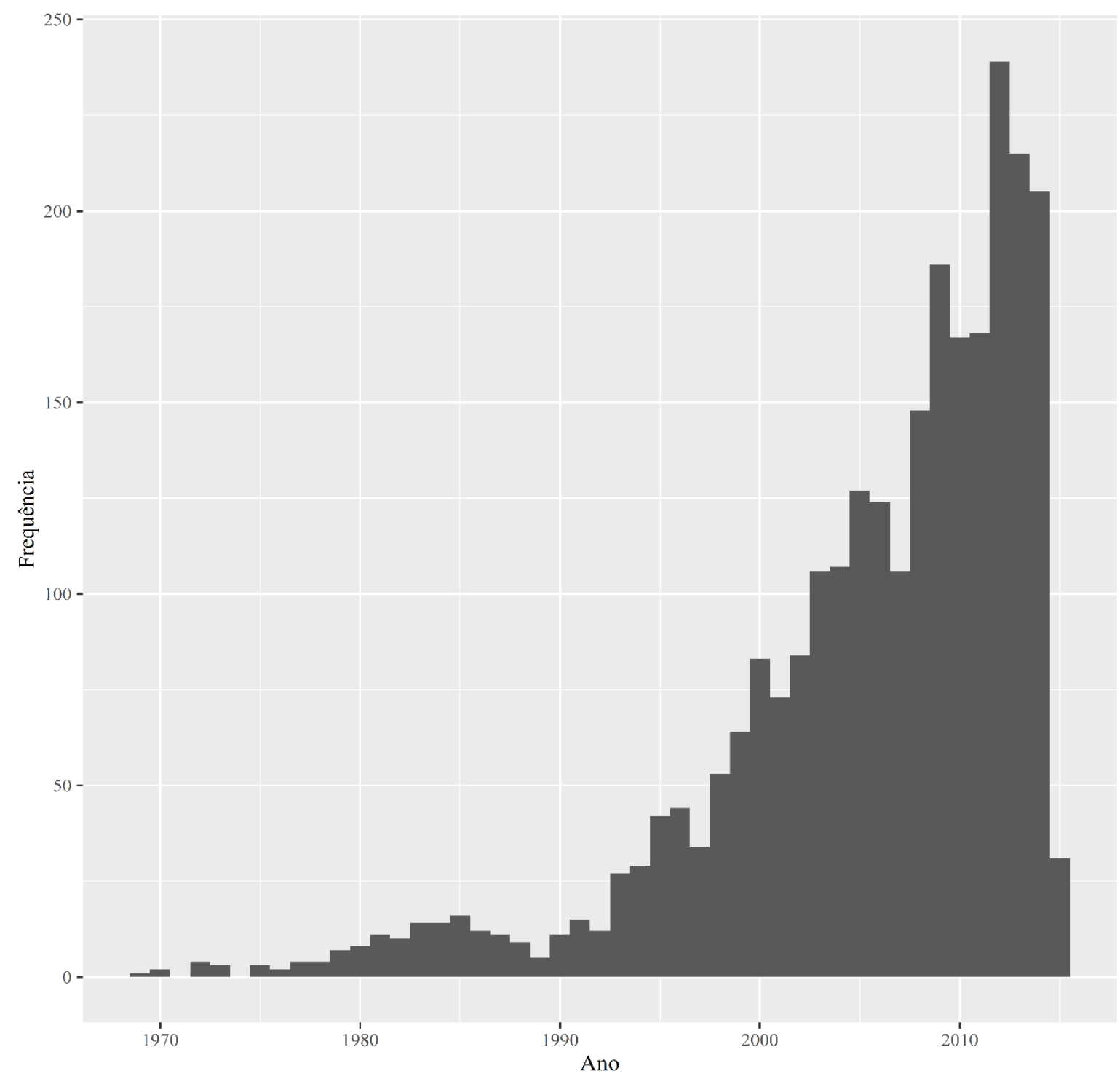

Figura 2. Histograma do Ano de Doutoramento

Uma informação interessante a respeito do perfil dos pesquisadores na área de Administração é a análise da localização geográfica dos acadêmicos. Com este objetivo, na Tabela 2, apresenta-se a divisão geográfica dos pesquisadores de Administração, assim como algumas estatísticas sobre produtividade. Como esperado, a Tabela 2 mostra que as três cidades com o maior número de pesquisadores de Administração são representadas por São Paulo (SP), Rio de Janeiro (RJ) e Brasília (DF). São Paulo possui uma alta concentração de pesquisadores, com mais do que o dobro de pesquisadores que o Rio de Janeiro, e mais do que o triplo de Brasília. Porém, quando se analisa as publicações em termos de fator de impacto (SJR), observa-se que o Rio de Janeiro possui um valor médio de 0,197, sendo mais elevado do que o valor médio em São Paulo, de 0,094. Vale destacar que Belo Horizonte apresenta uma maior porcentagem de bolsistas de produtividade do CNPq $(11,88 \%)$, seguido por Rio de Janeiro $(10,05 \%)$, Ribeirão Preto $(9,52 \%)$, Porto Alegre $(9,17 \%)$ e São Paulo $(8,91 \%)$. 
Tabela 2

Estatísticas de Publicação Científica da Área de Administração em Relação ao Domicílio do Pesquisador

\begin{tabular}{lccccc}
\hline Cidade & \# Pesquisadores & \# de publicações & $\begin{array}{c}\text { \% de bolsistas } \\
\text { de } \\
\text { produtividade }\end{array}$ & $\begin{array}{c}\text { Média de SJR } \\
\text { das publicações } \\
\text { com SJR }\end{array}$ & $\begin{array}{c}\text { Média de } \\
\text { pontos Qualis }\end{array}$ \\
\hline São Paulo, SP & 404 & 7007 & $8,91 \%$ & 0,094 & 52,97 \\
Rio de Janeiro, RJ & 189 & 3067 & $10,05 \%$ & 0,197 & 49,90 \\
Brasília, DF & 118 & 1552 & $4,24 \%$ & 0,091 & 48,43 \\
Porto Alegre, RS & 109 & 1922 & $9,17 \%$ & 0,074 & 48,49 \\
Florianópolis, SC & 107 & 2726 & $6,54 \%$ & 0,075 & 43,30 \\
Belo Horizonte, MG & 101 & 2374 & $11,88 \%$ & 0,112 & 47,42 \\
Curitiba, PR & 96 & 1804 & $6,25 \%$ & 0,058 & 40,82 \\
Salvador, BA & 71 & 1067 & $8,45 \%$ & 0,046 & 48,32 \\
Ribeirão Preto, SP & 63 & 1009 & $9,52 \%$ & 0,037 & 45,65 \\
Recife, PE & 53 & 986 & $5,66 \%$ & 0,046 & 39,24 \\
\hline
\end{tabular}

\section{Sobre as publicações}

Nesta seção serão analisadas as publicações encontradas no currículo Lattes dos pesquisadores em Administração. Uma investigação dos dados mostra que, assim como o número de doutores formados a cada ano, a quantidade de publicações apresenta uma trajetória ascendente juntamente com o número de novos periódicos. Para fins de comparação, 530 publicações foram registradas no ano de 2000, enquanto foram encontradas 5491 no ano de 2013, representando um crescimento próximo de 936\% de registros no período ${ }^{(4)}$.

Esse indicativo de crescimento no número de publicações, entre 2000 e 2013, necessita ser avaliado de forma qualificada, uma vez que não leva em consideração a estratificação das publicações. Para visualizar a evolução das publicações ao longo do tempo, apresenta-se a Figura 3, que mostra a evolução da percentagem de participação de cada estrato do Qualis da Administração em relação ao total de publicações para cada ano a partir de 1990. 


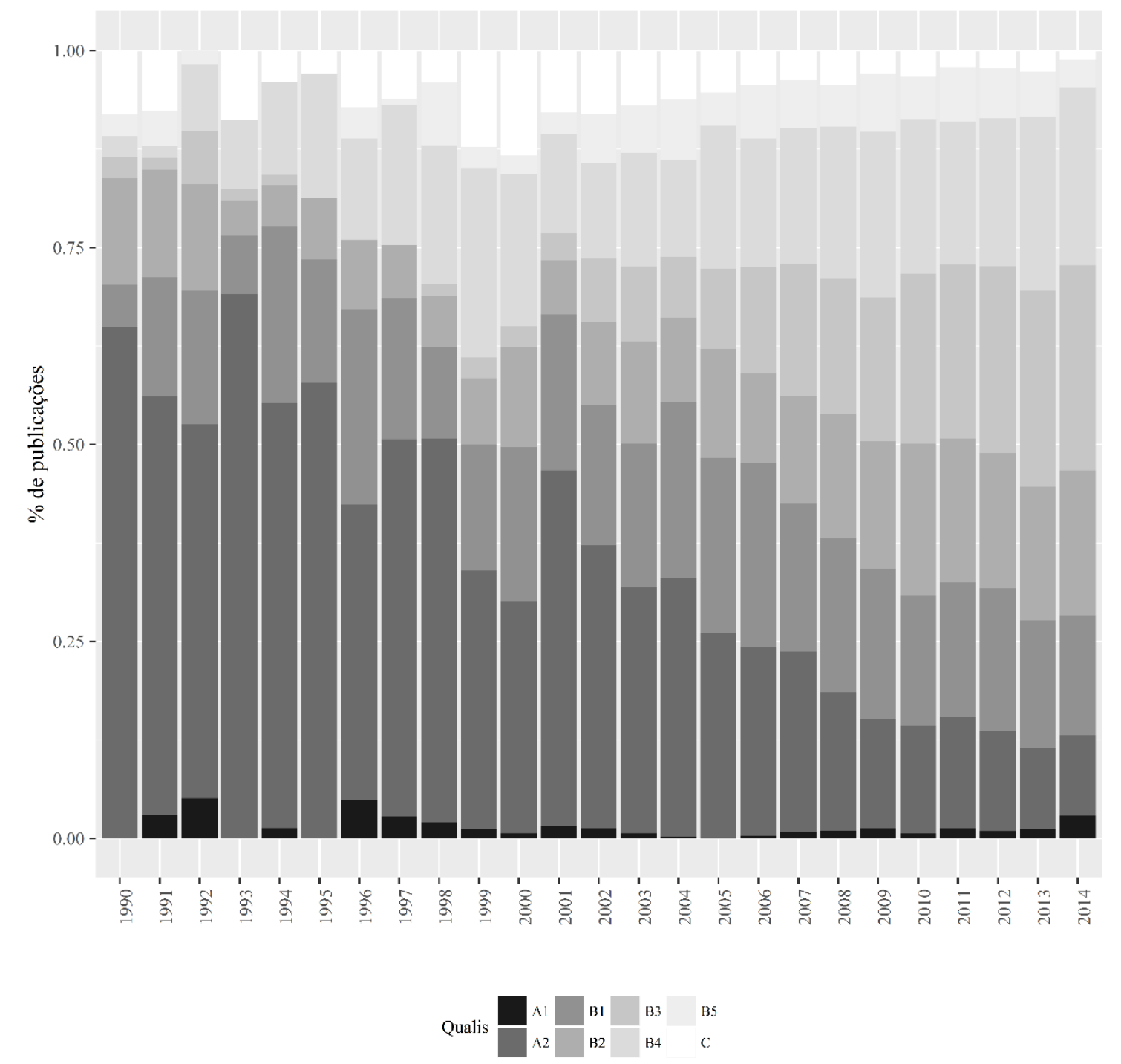

Figura 3. Percentagem de Cada Estrato Qualis para Cada Ano

A Figura 3 foi construída a partir do ISSN das publicações, que foi utilizado para verificar o estrato do periódico em que a publicação ocorreu. Conforme pode ser visto na Figura 3, o percentual de participação de estratos mais elevados do Qualis, particularmente os que foram classificados como A1 e A2, tem diminuído de forma sistemática ao longo do tempo. Por exemplo, em 2001, o percentual de participação de publicações A1 e A2 era de aproximadamente 50\%. Já em 2013, este percentual baixou para aproximadamente $17 \%$. A entrada de novos pesquisadores e de novos periódicos ajudou a impulsionar a quantidade de publicações no período. Por outro lado, essa situação suscita discussões sobre quantidade e qualidade das publicações da área, pois publicar mais não necessariamente é sinônimo de fazer pesquisas mais relevantes ou com impacto social ${ }^{(5)}$.

A Figura 4 apresenta a distribuição acumulada de artigos em relação à distribuição acumulada de autores. Apesar de seu formato contínuo, esta figura foi criada diretamente dos dados, sem qualquer tipo de suavização quantitativa. Conforme pode ser visto, existe uma grande concentração das publicações. Por exemplo, verifica-se que aproximadamente $17 \%$ dos autores correspondem a $50 \%$ do total de publicações. Ao se analisar a parte direita da distribuição, também se observa que $50 \%$ dos autores correspondem a $88 \%$ das publicações. Esta informação mostra claramente a existência de uma forte concentração das publicações, na qual poucos pesquisadores possuem um grande número de publicações. 


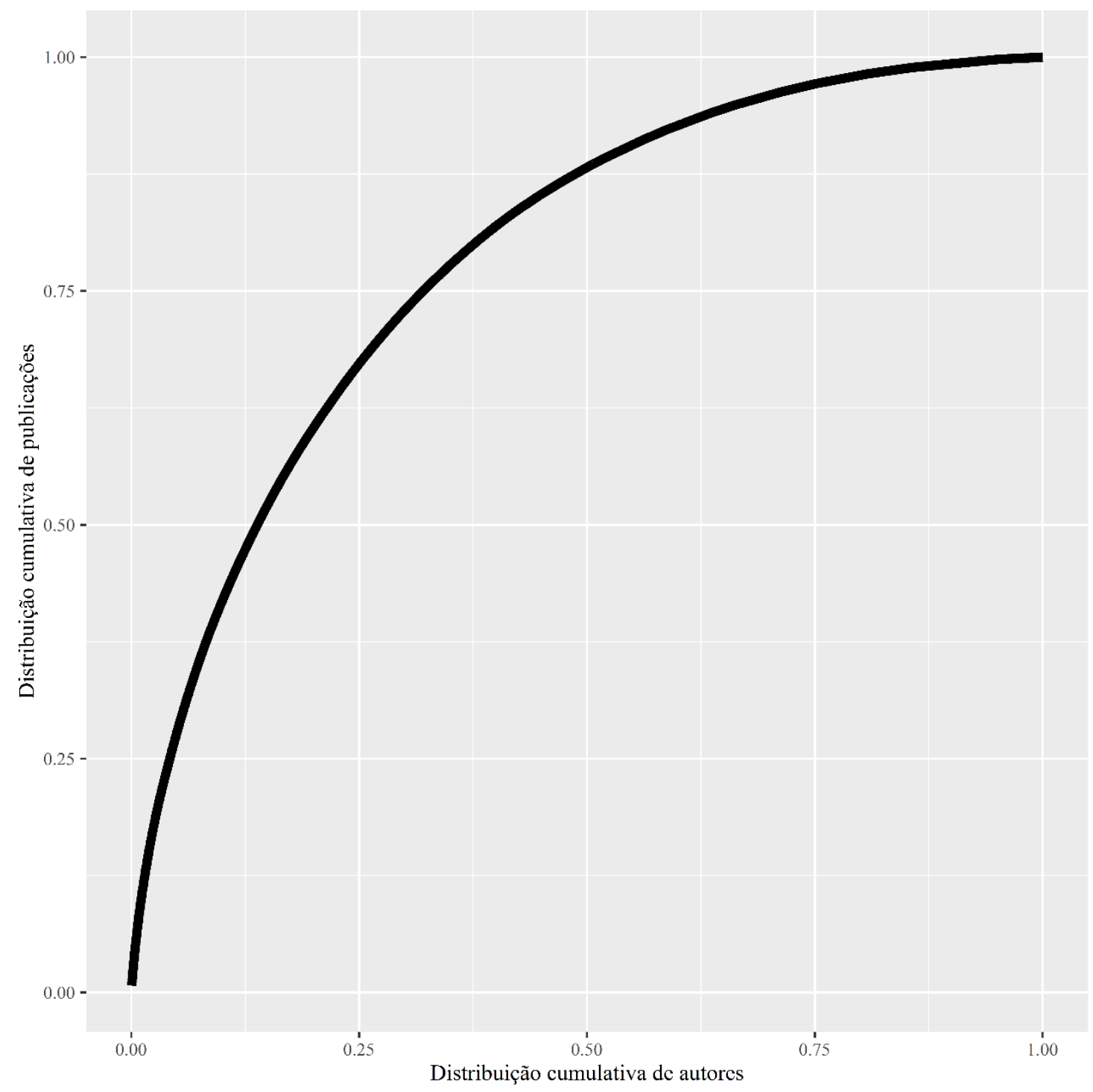

Figura 4. Distribuição Acumulada de Autores e Publicações

\section{Fatores da produtividade acadêmica}

Na seção anterior, observou-se que a qualidade das publicações, medida com base na lista Qualis, tem se modificado consideravelmente ao longo do tempo. Nesta seção, buscaremos entender quais são os fatores que explicam os diferentes níveis de produtividade científica dos pesquisadores. A Tabela 3 apresenta o resultado das estimações da Equação (1) para os dados da pesquisa. 
Tabela 3

Resultados da Estimação do Modelo (Equação (1))

\begin{tabular}{lcccc}
\cline { 2 - 5 } & $\begin{array}{c}\text { Dep }=\text { Média de } \\
\text { pontos qualis }\end{array}$ & $\begin{array}{c}\text { Dep =\# de } \\
\text { publicações por } \\
\text { ano }\end{array}$ & $\begin{array}{c}\text { Dep = Média de } \\
\text { SJR das } \\
\text { publicações }\end{array}$ & $\begin{array}{c}\text { Dep = \% de } \\
\text { publicações com } \\
\text { SJR }\end{array}$ \\
\hline Intercepto & $40.55^{* * *}$ & $7.60^{* * *}$ & $3.87^{* * *}$ & $10.88^{* * *}$ \\
Anos desde doutorado & $0.37^{* * *}$ & $-0.52^{* * *}$ & -0.10 & -0.14 \\
Anos desde doutorado & 0.00 & $0.01 * * *$ & 0.00 & $0.01^{*}$ \\
^2 & -0.10 & -0.07 & 0.12 & 0.33 \\
Intervalo de doutorado & $7.89 * * *$ & $3.01^{* * *}$ & $6.11^{* * *}$ & $8.66^{* * *}$ \\
D_BolsaProd & -0.09 & 0.16 & $1.98^{* * *}$ & 1.45 \\
D_DocFora & 0.10 & 0.16 & 0.03 & 0.04 \\
R $^{2}$ & 0.09 & 0.16 & 0.03 & 0.03 \\
Adj. R & & 1402 & 1402 & 1402 \\
Num. obs. & 1399 & & & \\
\hline
\end{tabular}

Nota. $* * * p<0.01, * * p<0.05, * \mathrm{p}<0.1$.

O primeiro resultado interessante na Tabela 3 é o efeito dos anos desde o doutorado sobre as diferentes métricas de produtividade em pesquisa. Observa-se que este efeito é positivo para a explicação da média dos pontos utilizando o Qualis, indicando a importância da experiência do acadêmico em termos de produtividade científica. Já para o caso do número de publicações por ano, observa-se que o coeficiente atrelado a Anos desde Dout é negativo, enquanto que para o seu valor ao quadrado é positivo. Isto indica um efeito curvilíneo, no qual existe um declínio de produtividade no curto prazo da carreira do pesquisador, porém um aumento no longo prazo. Contudo, para os casos da média de SJR, tal relação não é significativa, indicando que o tempo desde a obtenção do doutorado de um investigador não afeta o impacto de sua pesquisa, considerando o SJR dos periódicos.

Para o intervalo de doutorado, observa-se que o efeito do mesmo não é significativo. Isto indica que o tempo necessário para terminar o doutorado não tem poder explicativo sobre as diferentes proxies de produtividade científica.

Quando se verifica o impacto da bolsa de produtividade, observa-se uma correlação positiva e significativa com as quatro proxies utilizadas na pesquisa. Isto é, os pesquisadores com bolsa de produtividade são aqueles com maior média de pontos Qualis, maior número de artigos publicados por ano, maior valor médio de SJR e maior percentagem de trabalhos indexados em revistas com fator de impacto do tipo SJR. Este resultado era esperado, pois a bolsa seleciona os pesquisadores de acordo com a sua produtividade. Portanto, a constatação dessa alta correlação entre a existência de bolsa de produtividade e a respectiva produtividade científica do pesquisador ajuda a indicar a robustez dos dados da pesquisa.

Para o caso do efeito do doutorado fora do Brasil sobre as proxies de produtividade, verifica-se uma correlação positiva e significativa com o SJR médio. Este resultado indica que pesquisadores que tiveram a sua formação de doutorado fora do Brasil apresentam maiores índices de publicações em periódicos com fator de impacto. Esse resultado pode indicar que pesquisadores com doutorado fora do Brasil tendem, na média, a focar mais o impacto de suas pesquisas e não a quantidade de artigos publicados. 


\section{Discussão dos Resultados}

A presente pesquisa indicou características do perfil dos pesquisadores e de suas correspondentes produções em periódicos científicos, o que é importante para refletir e analisar o atual momento da área de Administração no Brasil. Um primeiro ponto de reflexão é em relação ao aumento da quantidade de pesquisadores com doutorado vinculados a esse campo de atuação. Esse crescimento de pesquisadores atuando em Administração foi indicado no planejamento formulado pela CAPES para a pós-graduação stricto-sensu no Brasil ao longo das décadas de 1990 e de 2000. Formalizadas no Plano Nacional de Pós-Graduação (PNPG), as políticas da CAPES para os períodos de 2005 a 2010 (CAPES, 2004) e de 2011 a 2020 (CAPES, 2010) definiram o objetivo de expansão do número de programas e da quantidade de mestres e doutores formados no país, em todas as diferentes áreas de atuação, como esforço de consolidação da pós-graduação no Brasil.

O Plano tem como um dos seus objetivos fundamentais uma expansão do sistema de pósgraduação que leve a expressivo aumento do número de pós-graduandos requeridos para a qualificação do sistema de ensino superior do país, do sistema de ciência e tecnologia e do setor empresarial. (CAPES, 2004, p. 9)

Pelos resultados obtidos, pode-se observar que o substancial aumento na quantidade de novos pesquisadores doutores na área é consistente com esse planejamento institucional. A visualização do histograma da Figura 2 permite concluir que a base de pesquisadores em Administração é de doutores com pouco tempo de doutoramento, dado o expressivo aumento quantitativo de egressos a partir de 2000. Na medida em que o PNPG para o período de 2011 a 2020 ainda preconiza o aumento de programas e de número de formandos em pós-graduação, é de se presumir que a quantidade de mestres e doutores titulados siga aumentando até o final da década. Considerado esse contexto, outro ponto de reflexão para os próximos anos será o de analisar quais serão os impactos do contínuo aumento de doutores na área, tanto em termos de produtividade científica como de inserção profissional.

Países como Estados Unidos, Japão, Alemanha, China e Índia vêm sinalizando preocupações com relação ao número crescente de doutores, formados em diversas áreas nas últimas décadas, pois há uma tendência de que não haja disponibilidade de posições de trabalho suficientes para esse contingente de pessoas (Cyranoski, Gilbert, Ledford, Nayar, \& Yahia, 2011). Nesses termos, a própria lógica de formação e de inserção desses profissionais poderá demandar uma revisão no Brasil para as próximas décadas, inclusive na área de Administração, pois a elevada quantidade de titulados tende a ser um problema análogo aos dos países citados anteriormente ${ }^{(6)}$.

Tendo como base de dados os doutores atuando no Brasil, entre 1996 e 2008, a pesquisa da CGEE (2010), realizada em todas as áreas científicas, indicou haver forte concentração tanto de formação de doutores como de postos de trabalhos na região Sudeste. Essa pesquisa apontou que $77 \%$ dos doutores foram titulados por instituições do Sudeste no período em questão, enquanto que 53\% dos doutores, em 2008, tinham posição de trabalho na região.

Quando se considera a distribuição do emprego em 2008 entre as unidades da federação, também se observa um elevadíssimo grau de concentração. As cinco unidades da federação que mais empregavam, no ano de 2008, doutores que obtiveram seus títulos em 1996, eram os estados de São Paulo (42,8\%), Rio de Janeiro (14,6\%), Minas Gerais (9,6\%), Rio Grande do Sul (6\%) e Paraná (5,9\%). Essas cinco unidades da federação empregavam, em 2008, 78,9\% dos titulados em 1996. (CGEE, 2010, p. 36)

O aumento de doutores nos próximos anos poderá ser um elemento que incrementará complexidade ao tema da inserção profissional. Pesquisas futuras poderão investigar se elementos de produtividade científica podem ser considerados como fatores que explicam a distribuição de empregos e de inserção profissional na área de Administração (Lissoni et al., 2011). Questões de mobilidade de acadêmicos entre instituições e entre cidades também poderão ser pontos de investigações futuras. 
Em relação às subáreas de especialidade de atuação, a classificação padrão disponibilizada pela Plataforma Lattes não se mostrou adequada para fins de delimitação e vinculação das atividades dos pesquisadores. Há três áreas conectadas com Administração Pública (política e planejamento governamentais, organizações públicas, e contabilidade e finanças públicas), sendo que contabilidade está, atualmente, inserida junto a finanças públicas. Subáreas de atuação como a de estratégia, empreendedorismo, estudos organizacionais, administração da informação e ensino e pesquisa em administração, por exemplo, ficaram ausentes. Algumas das áreas de atuação disponíveis nas divisões acadêmicas da Associação Nacional de Pós-Graduação e Pesquisa em Administração (ANPAD) podem servir de base para uma revisão dessas áreas no sistema do currículo Lattes. Essas informações são relevantes para indicar elementos demográficos do perfil dos pesquisadores, informando com maior qualidade as suas respectivas áreas de atuação. A partir de uma atualização dessas áreas de atuação, seria possível analisar comparativamente as peculiaridades das subáreas, o que não pode ser adequadamente analisado e delineado nesta pesquisa devido a essa restrição na qualidade dos dados existentes.

Os resultados da pesquisa também permitem destacar, com base em dados quantitativos, questões que são relevantes para discussões sobre a produtividade científica na área de Administração. Uma das questões recorrentes, que indica que a qualidade tem sido preterida pela quantidade (Bertero, Caldas \& Wood, 1999; CAPES, 2010; Freitas, 2011), encontra suporte nesta análise. A preocupação com quantidade fica evidenciada na medida em que se constata o expressivo aumento no número de artigos publicados ao longo do tempo, principalmente com a observância de um maior crescimento de publicação nos estratos B2, B3 e B4, com ilustra a Figura 3. Possíveis explicações para essa predileção por periódicos intermediários do Qualis podem passar pela menor competição por aceitação para publicação e menor taxa de reprovação. Uma análise mais aprofundada dos dados também mostra a alta concentração das publicações para os mesmos pesquisadores, conforme pode ser visualizado na Figura 4. Seria interessante também explicar, em investigações futuras, a razão pela qual uma grande parcela de acadêmicos em Administração possui tão baixa produção científica em periódicos com fator de impacto em bases como SJR e acrescentar nome por extenso (ISI).

Observou-se, ainda, uma tendência de que pesquisadores com doutorado fora do Brasil tenham mais publicações em periódicos SJR, sendo um fator de produtividade científica identificado na pesquisa. Uma linha de argumentação para esse resultado é a de que a exposição à dinâmica acadêmica no exterior pode auxiliar os acadêmicos formados em outros países a desenvolver habilidades compatíveis para a efetiva publicação nesses periódicos, principalmente se buscarem publicar durante o doutoramento (Horta \& Santos, 2016). Outra explicação é a de que o ambiente acadêmico nas universidades no exterior estimula o futuro pesquisador a se conformar ao uso de abordagens teóricas e metodológicas aceitas nesses periódicos, particularmente nos mais bem classificados (ver Adler \& Harzing, 2009; Rond \& Miller, 2005). A efetiva explicação dos motivos de existência de diferença de desempenho, na média, em termos de produtividade científica em publicação em periódicos indexados no SJR, seria uma linha de pesquisa a ser mais bem investigada.

O efeito conjunto do contínuo aumento de doutores na área, de um número mais reduzido de periódicos mais bem classificados no Qualis (i.e., A1 e A2) e uma maior cobrança por produtividade científica dos pesquisadores, tanto pela avaliação da CAPES quanto pelos programas de pós-graduação, ainda é incerto. Entretanto, é de se presumir que esse conjunto de fatores produzirá condições de trabalho mais adversas, considerando-se o crescente aumento da competitividade por empregos, por espaços de publicação, por recursos de pesquisa e maior exigência nas avaliações institucionais. Esta mudança, contudo, poderá ser acompanhada por um período de instabilidade nos programas de pós-graduação. Essa possibilidade já tem sido explorada em alguns estudos, nacional e internacionalmente, ressaltando temas como a deterioração nas condições de trabalho, uma maior propensão a condutas acadêmicas impróprias e a possibilidade de perda de qualidade e relevância nas publicações científicas (e.g., Anderson et al., 2007; Machado \& Bianchetti, 2011; Miller et al., 2011). Análises aprofundadas dos efeitos específicos para acadêmicos e suas correspondentes instituições de ensino e pesquisa na área de Administração ainda necessitam de maior atenção como um campo de pesquisa específico.

Em termos de produções científicas, a avaliação institucional da CAPES tem papel relevante no direcionamento dos esforços e na definição de políticas acadêmicas. Em particular, a produção 
intelectual é um item de destaque nessas avaliações da CAPES, sendo que a lista Qualis possibilitou a criação de uma sistemática de cálculo de desempenho que passou a ser considerada como uma métrica de qualidade no processo avaliativo dos programas de pós-graduação. Apesar de a sistemática parecer conferir uma impessoalidade e precisão, há questionamentos em parte oriundos da comunidade acadêmica e que têm sido formalizados como parte do documento de planejamento da CAPES, para a década de 2010, como questão de discussão dos problemas enfrentados na pós-graduação no Brasil (CAPES, 2010).

O destaque feito sobre a discussão entre quantidade e qualidade também está relacionado com a sistemática de avaliação da CAPES na área de Administração que, conforme os críticos, privilegia sobremaneira a quantidade de publicações, uma vez que a avaliação institucional confere demasiada atenção aos sistemas de classificação da lista Qualis e exacerba a avaliação centrada na quantidade dos indicadores. Isso faz com que considerações sobre relevância, inovação, qualidade e formação se tornem questões secundárias (Bertero et al., 1999; Bertero, Vasconcelos, Binder, \& Wood, 2013; Freitas, 2011). Observa-se que há uma tendência de padronização das publicações desde 2004, conforme ilustra a Figura 4 da pesquisa, na qual os estratos passaram a ter padrões de distribuições mais bem definidos, com predominância dos estratos intermediários (B1, B2 e B3). Alguns casos extremos chamam a atenção. Existe um autor com 27 publicações em periódicos B3 no ano de 2004, isto é, com 2,25 publicações por mês, resultando em uma pontuação de 1350 na avaliação da CAPES.

$\mathrm{Na}$ ausência de consenso em como definir qualidade na avaliação da CAPES, é de se supor que a métrica estipulada como sistemática de avaliação de publicações passou a ser adotada como meta para os acadêmicos nos programas de pós graduação, utilizado como orientação de políticas acadêmicas para fins administrativos. Na área de Administração, na avaliação do triênio 2010-2012, as médias anuais de publicação foram utilizadas como meio de avaliação da produção intelectual dos programas, sendo um dos indicadores a proporção de docentes com pelo menos 150 pontos de produção bibliográfica. Possíveis maneiras de lidar com essa questão seriam a já disponível inclusão do número de citação dos artigos em bases consolidadas de artigos como o ISI e o SCOPUS.

Uma possível linha de pesquisa a ser explorada no futuro, decorrente dessas observações, é a de analisar o impacto dos sistemas de avaliação acadêmicos, particularmente aqueles que estratificam os periódicos científicos como o Qualis, na produção científica. A própria pesquisa aqui desenvolvida utilizou tanto uma média de pontos Qualis quanto uma média de SJR das publicações como atributos do perfil dos pesquisadores, o que denota o potencial de construção de padronizações dessas métricas. A pesquisa realizada não obteve indícios que permitam refutar o pressuposto, levantado pelos autores que criticam o produtivismo, de que o Qualis cria um sistema que incentiva a produção de artigos em quantidade. Pesquisas futuras que analisem aspectos da relação entre quantidade e qualidade necessitarão de maior aprofundamento. No Brasil, é possível que o foco em quantidade possa atender a uma parcela da própria comunidade da área de Administração, avalizando a sistemática calcada no cálculo de pontos por questões pragmáticas (Freitas, 2011). Ademais, a inclusão de outras formas de produção científica, tal como o livro, é um desafio em termos de análise de produtividade científica. A questão de como e até que ponto as métricas existentes podem ser associadas com qualidade e relevância em avaliações de desempenho, em um campo de conhecimento heterogêneo e com pouco tempo de existência como o da Administração, será um importante ponto de discussão para o amadurecimento e desenvolvimento da área (Adler \& Harzing, 2009; Alcadipani, 2011; Bertero et al., 2013).

Outro efeito colateral decorrente das pressões por publicações, que vem ocorrendo em diversos países, é o da proliferação de periódicos que, com o intuito de facilitar a publicação de artigos ou de gerar lucros, passaram a publicar documentos de toda espécie, mediante pagamento, que tivesse um formato de similitude a de um artigo científico, mas sem os cuidados necessários acerca do conteúdo, os quais têm sido chamados de periódicos predatórios (Beall, 2012). Algumas dessas revistas foram inseridas na lista do Qualis e no SJR, o que denota a necessidade de se ter precaução em uma associação direta entre Qualis-SJR e qualidade (Adler \& Harzing, 2009; Domingues, 2014; Freitas, 2011; Rond \& Miller, 2005; Starbuck, 2005). Os cuidados com periódicos predatórios são de extrema importância, uma vez que há vantagens que podem ser adquiridas com a fácil publicação nesses periódicos (e.g., 
avaliação institucional), o que pode incentivar essa forma de atuação. Isso pode comprometer a credibilidade de todo o sistema de avaliação de publicações.

É necessário ter cautela, portanto, nos usos de mensurações para fins públicos. Como ressalta Theodore M. Porter (1994), as "métricas para propósitos públicos raramente são tão simples como aplicar uma régua" (p. 391), o que é observável nas dificuldades enfrentadas pelas avaliações da CAPES. A perda da credibilidade nas publicações e nos próprios instrumentos de avaliação podem causar graves problemas para as instituições de ensino e pesquisa de pós-graduação. Se há críticas e questionamentos para as métricas existentes, os indicativos são de que elas ainda não estão plenamente desenvolvidas para avaliar o desempenho acadêmico, reforçando a necessidade de aprofundamento de sua compreensão para fins de consideração da produtividade científica. Há notáveis obstáculos a serem ultrapassados na realização dessa complexa tarefa de avaliação de desempenho.

O maior desafio permanece sendo o de lidar com uma adequada quantificação de qualidades (Porter, 1994). Para continuar a desenvolver os usos de quantificação, é importante ressaltar que se deve avaliar não apenas a validade da métrica em si, como também "sobre como o mundo pode ser mudado pela adoção de novas formas de quantificação" (Porter, 1994, p. 404). Os resultados desta pesquisa indicam características de perfil de acadêmicos e alguns padrões de publicações que têm sofrido influências das políticas institucionais de avaliação da pós-graduação. A avaliação e controle dos acadêmicos e das suas produções científicas correspondentes são uma demanda pública, a despeito da resistência dos próprios acadêmicos em serem avaliados. Isso é uma tarefa complexa e de difícil execução porque há diferentes especificidades e formas de se definir desempenho acadêmico no campo científico (ver Lane, 2010), muitas das quais são de difícil padronização ou mensuração. Todavia, é inegável que esses esforços moldam e modificam a própria forma como o ofício acadêmico é concebido e executado, o que merecerá atenção em termos de investigações futuras.

\section{Conclusões}

A presente pesquisa analisou o perfil de acadêmicos doutores que atuam na área de Administração no Brasil e as suas respectivas publicações científicas, tendo como base de referência dados oriundos da Plataforma Lattes. Em nosso modelo econométrico, quatro variáveis foram definidas como explicativas para mensurar a produtividade científica em publicação de periódicos: (a) anos desde o doutorado; (b) duração do doutoramento; (c) existência de bolsa de produtividade do $\mathrm{CNPq}$ e (d) realização de doutorado fora do país. Esse modelo foi construído com base em pesquisas análogas realizadas em outros países, que tinham disponíveis outras bases de dados, adaptando parte das categorias analíticas para que pudessem ser empregadas no contexto brasileiro. A pesquisa foi um primeiro passo no sentido de uma análise do perfil dos pesquisadores e de suas respectivas publicações científicas utilizando uma grande base de dados.

O trabalho identificou fatores ligados à formação e experiência que influem, na média, a produtividade científica de acadêmicos em Administração, dos quais se destacam os seguintes aspectos: (a) a bolsa de produtividade é um fator positivo e significativo na produtividade científica; (b) a realização de doutorado no exterior se mostrou um fator positivo para produtividade de artigos publicados em periódicos listados no SJR; (c) o efeito do tempo desde o término do doutorado tem influência na produtividade ao longo do tempo e (d) o intervalo de doutoramento não possuiu efeito significativo na produtividade.

Em um momento em que há acalorados debates no âmago da sociedade em relação às instituições acadêmicas, a presente pesquisa analisa dados que materializam as discussões, sendo uma das pioneiras na operacionalização de análises de produtividade científica no campo da Administração no Brasil, pois teve como suporte uma vasta base de dados de doutores e a utilização de métodos estatísticos. Foram encontradas importantes mudanças na forma como os acadêmicos da área publicam, com a constatação de um expressivo aumento na quantidade de artigos publicados e do crescimento dos estratos 
intermediários, tendo como base a lista Qualis de 2014. Houve também a identificação de um crescimento considerável do número de doutores formados publicando na área de Administração a partir do ano de 2000.

Por trabalhar com uma vasta base de dados, houve algumas limitações na condução da pesquisa. Questões de perfil dos acadêmicos, tais como idade, gênero, trajetória profissional, entre outros possíveis fatores, não puderam ser trabalhadas adequadamente nesta pesquisa. Houve limitações no processo de filtragem dos acadêmicos com base nas áreas de atuação. A múltipla contagem do mesmo artigo também se constitui em uma limitação, uma vez que, pelo método de coleta de dados utilizado, não foi possível analisar o número exato de artigos científicos únicos publicados, podendo ter gerado algum viés para os resultados, que infelizmente não tivemos condições de identificar. A produtividade científica ficou restringida, nesta pesquisa, à publicação de artigos em periódicos indexados. Os demais elementos da produção acadêmica, tais como aulas lecionadas, orientações, atividades de extensão, entre outros, não puderam ser considerados para fins de uma análise da produtividade científica em uma concepção mais ampla.

Destaque-se ainda que, em termos de limitações do método, quando da construção do modelo econométrico, a variável $\operatorname{Pr} o d A c_{i}$, ao utilizar as proxies de produtividade científica, fez uso da média de SJRs e realizou duas aproximações: (a) atribuiu à escala SJR o valor igual a zero para os artigos sem fator de impacto; (b) assumiu que a escala atende ao princípio da unidade em todos os seus níveis. Adicionalmente, não houve a possibilidade de análise de elementos como gênero, idade e de posição acadêmica nesta pesquisa, que são elementos trabalhados na literatura, limitando as análises realizadas no presente estudo. Assim, ainda há lacunas a serem trabalhadas pelos interessados no assunto, de modo a melhor contextualizar as variáveis que explicam a produção científica de artigos na área de Administração no Brasil.

A despeito das limitações, a linha de trabalho tratada nesta pesquisa indica a pertinência e a relevância do aprofundamento de pesquisas relacionadas à produtividade científica e produção acadêmica. Esperamos que os resultados dessa pesquisa ajudem a fundamentar as discussões sobre os rumos da produção intelectual e da pós-graduação em Administração no Brasil em anos futuros.

\title{
Notas
}

\begin{abstract}
${ }^{1}$ A decisão de utilizar a listagem do Qualis como benchmarking e a de proceder ao corte daqueles acadêmicos que não apresentaram ao menos $50 \%$ da produção científica em Administração carrega, sem dúvida, um componente institucional da própria avaliação da produtividade científica organizada pela CAPES. Como indica Parker et al. (1998), usando o Reino Unido e a Austrália como exemplos, é de se esperar que esse grupo de avaliadores moldem a noção sobre o que é a área por meio das publicações, tendo como referência o seu próprio viés. Entretanto, uma rápida inspeção na lista do Qualis mostra que existe um bom número de periódicos compartilhados com outras áreas de avaliação na lista da Administração, tais como da Engenharia, Educação e Economia, o que ajuda a dirimir eventuais erros de corte. Por outro lado, incluir uma porcentagem maior que 50\% poderia fazer com que pesquisadores que não tem nenhuma vinculação com a área passassem a compor a base analisada, o que comprometeria a investigação. Nesses termos, entendemos que a escolha de um ponto de corte em $50 \%$ é razoável em relação aos objetivos da pesquisa.

${ }^{2}$ Os dados de produção anteriores a 1990 não foram utilizados porque é pequeno o volume de publicações anteriores a este ano em comparação com anos mais recentes. Para o limite superior, utilizamos o ano de 2014.

${ }^{3} \mathrm{O}$ modelo de regressão de Rorstad e Aksnes (2015), baseado no banco de dados norueguês, tinha à disposição dois dados aos quais não tivemos acesso no Lattes: idade e gênero. Em relação ao gênero, considerando o tamanho da base de dados, não foi possível uma análise específica dessa variável no presente trabalho, constituindo-se como uma limitação do modelo. Em relação à idade, utilizou-se o tempo desde o doutoramento como uma variável substituta. Apesar de não terem a mesma qualidade de informação, ambas indicam o elemento temporal, obtendo resultados analíticos análogos.
\end{abstract}

${ }^{4}$ É preciso frisar que esse aumento é relativo ao número de registro de publicações não únicas, ou seja, no caso de haver dois ou mais autores por artigo, o mesmo artigo poderá ter múltiplos registros, um em cada currículo no Lattes. Não foi possível precisar, na presente pesquisa, a quantidade exata de artigos, constituindo-se em uma limitação da investigação.

${ }^{5} \mathrm{O}$ aumento do número de publicações não veio acompanhado de um acréscimo na quantidade de periódicos mais bem classificados na mesma proporção, tendo como referência o estrato do Qualis dos periódicos em Administração. A comissão 
da área de Administração estabeleceu, no ano de 2013, que a soma de periódicos classificados como A1 e A2 no Qualis não poderia ultrapassar $25 \%$ do total da listagem de periódicos indexados, indicando que há uma preocupação em manter alguma restrição do que é considerado como de maior qualidade ou prestígio pela área.

${ }^{6}$ É pertinente considerar, todavia, o alerta de que as eventuais reavaliações de programas de doutoramento não devam se limitar a tratar apenas de elementos de eficiência e empregabilidade, uma vez que devem considerar, também, as necessidades da sociedade e as políticas públicas envolvidas nessa questão.

\section{Referências}

Adler, N. J., \& Harzing, A.-W. (2009). When knowledge wins: transcending the sense and nonsense of academic rankings. Academy of Management Learning Education, 8(1), 72-95. http://dx.doi.org/10.5465/AMLE.2009.37012181

Alcadipani, R. (2011). Resistir ao produtivismo: uma ode à perturbação Acadêmica. Cadernos EBAPE.BR, 9(4), 1174-1178. 39512011000400015

Anderson, M. S., Ronning, E. A., De Vries, R., \& Martinson, B. C. (2007). The perverse effects of competition on scientists' work and relationships. Science and Engineering Ethics, 13(4), 437461. http://dx.doi.org/10.1007/s11948-007-9042-5

Beall, J. (2012). Predatory publishers are corrupting open access. Nature, 489(7415), 179. http://dx.doi.org/10.1038/489179a

Bertero, C. O., Caldas, M. P., \& Wood, T., Jr. (1999). Produção científica em administração de empresas: provocações, insinuações e contribuições para um debate local. Revista de Administração $\quad$ Contemporânea, $\quad 3(1), \quad$ 147-178. http://dx.doi.org/10.1590/S141565551999000100009

Bertero, C. O., Vasconcelos, F. C., Binder, M. P., \& Wood, T., Jr. (2013). Produção científica brasileira em Administração na década de 2000. Revista de Administração de Empresas, 53(1), 12-20. http://dx.doi.org/10.1590/S0034-75902013000100002

Centro de Gestão e Estudos Estratégicos. (2010). Doutores 2010: estudos da demografia da base técnico-científica brasileira. Brasília: Autor.

Cooper, S., \& Poletti, A. (2011). The new ERA of journal ranking. Australian Universities Review, 53(1), 57-65.

Coordenação de Aperfeiçoamento de Pessoal de Nível Superior. (2004). Plano nacional de pósgraduação-PNPG 2005-2010. Brasília: Autor.

Coordenação de Aperfeiçoamento de Pessoal de Nível Superior. (2010). Plano nacional de pósgraduação-PNPG 2011-2020. Brasília: Autor.

Cyranoski, D., Gilbert, N., Ledford, H., Nayar, A., \& Yahia, M. (2011). The PhD factory. Nature, 472(7343), 276-279. http://dx.doi.org/10.1038/472276a

Domingues, I. (2014). O sistema de comunicação da ciência e o taylorismo acadêmico: questionamentos e alternativas. Estudos Avançados, 28(81), 225-250. http://dx.doi.org/10.1590/S010340142014000300014

Freitas, M. E. (2011). O pesquisador hoje: entre o artesanato intelectual e a produção em série. Cadernos EBAPE.BR, 9(4), 1158-1163. http://dx.doi.org/10.1590/S1679-39512011000400013 
Gad-el-Hak, M. (2004). Publish or perish - an ailing enterprise? Physics Today, 57(3), 61-62. http://dx.doi.org/10.1063/1.1712503

Godoi, C. K., \& Xavier, W. G. (2012). O produtivismo e suas anomalias. Cadernos EBAPE.BR, 10(2), 456-465. http://dx.doi.org/10.1590/S1679-39512012000200012

Hoepner, A. G. F., \& Unerman, J. (2012). Explicit and implicit subject bias in the ABS Journal Quality Guide. Accounting Education, 21(1), 3-15. http://dx.doi.org/10.1080/09639284.2011.651291

Horta, H., \& Santos, J. M. (2016). The impact of publishing during PhD studies on career research publication, visibility, and collaborations. Research in Higher Education, 57(1), 28-50. http://dx.doi.org/10.1007/s11162-015-9380-0

Lane, J. (2010). Let's make science metrics more scientific. Nature, 464(7288), 488-489. http://dx.doi.org/10.1038/464488a

Leite, B. D., Oliveira, E. A., Queiroz, I. N., Martelli, D. R., Oliveira, M. C., \& Martelli, H., Jr. (2012). Perfil dos pesquisadores com bolsa de produtividade no Conselho Nacional de Desenvolvimento Científico e Tecnológico (CNPq) da área da educação física. Motricidade, 8(3), 90-98. http://dx.doi.org/10.6063/motricidade.8(3).1160

Lissoni F., Mairesse J., Montobbio, F., \& Pezzoni, M. (2011). Scientific productivity and academic promotion: a study on French and Italian physicists. Industrial and Corporate Change, 20(1), 253-294. http://dx.doi.org/10.1093/icc/dtq073

Machado, A. M. N., \& Bianchetti, L. (2011). (Des)Fetichização do produtivismo acadêmico: desafios para o trabalhador-pesquisador. Revista de Administração de Empresas, 51(3), 244-254. http://dx.doi.org/10.1590/S0034-75902011000300005

McGrail, M. R., Rickard, C. M., \& Jones, R. (2006). Publish or perish: a systematic review of interventions to increase academic publication rates. Higher Education Research \& Development, 25(1), 19-35. http://dx.doi.org/10.1080/07294360500453053

Miller, A. N., Taylor, S. G., \& Bedeian, A. G. (2011). Publish or perish: academic life as management faculty live it. Career Development International, 16(5), 422-445. http://dx.doi.org/10.1108/13620431111167751

Parker, L., Guthrie, J., \& Gray, R. (1998). Accounting and management research: passwords from the gatekeepers. Accounting, Auditing and Accountability Journal, 11(4), 371-402. http://dx.doi.org/10.1108/09513570510584638

Pegino, P. M. F. (2014). As relações acadêmicas de produção na pós-graduação em Administração no Brasil (Tese de doutorado). Fundação Getulio Vargas, São Paulo, SP, Brasil.

Porter, T. M. (1994). Making things quantitative. Science in Context, 7(3), 389-407. http://dx.doi.org/10.1017/S0269889700001757

Rafols, I., Leydesdorff, L., O'Hare, A., Nightingale, P., \& Stirling, A. (2012). How journal rankings can suppress interdisciplinary research: a comparison between Innovation Studies and Business \& $\begin{array}{llll}\text { Management. } \quad \text { Research } & \text { 1262-1282. }\end{array}$ http://dx.doi.org/10.1016/j.wasman.2012.01.017

Rond, M., \& Miller, A. N. (2005). Publish or perish: bane or boon of academic life? Journal of Management Inquiry, 14(4), 321-329. http://dx.doi.org/10.1177/1056492605276850

Rorstad, K., \& Aksnes, D. W. (2015). Publication rate expressed by age, gender and academic position: a large-scale analysis of Norwegian academic staff. Journal of Informetrics, 9(2), 317-333. http://dx.doi.org/10.1016/j.joi.2015.02.003 
Ross, D. H., Calabró, L., Jesus, S. L., Souza, D. O., Barbosa, N. V., \& Rocha, J. B. T. (2014). Brazilian scientific production in areas of biological sciences: a comparative study on the modalities of full doctorate in Brazil or abroad. Scientometrics, 98(1), 415-427. http://dx.doi.org/10.1007/s11192013-1017-5

Starbuck, W. H. (2005). How much better are the most-prestigious journals? The statistics of academic publication. Organization Science, 16(2), 180-200. http://dx.doi.org/10.1287/orsc.1040.0107

Souto, R. Q., Lacerda, G. S., Costa, G. M. C., Cavalcanti, A. L., França, I. S. X., \& Sousa, F. S. (2012). Characterization of the productivity of scholar researchers of CNPq of nursing: a cross-sectional study. Online Brazilian Journal of Nursing, 11(2), 261-273. http://dx.doi.org/10.5935/16764285.20120025

Van Dalen, H., \& Henkens, K. (2012). Intended and unintended consequences of a publish-or-perish culture: a worldwide survey. Journal of the American Society for Information Science and Technology, 63(7), 1282-1293. http://dx.doi.org/10.1002/asi.22636

\title{
Dados dos Autores
}

\author{
Takeyoshi Imasato \\ Rua Washington Luiz, 855, 90010-460, Porto Alegre, RS, Brasil. E-mail: t.imasato@ufrgs.br \\ Marcelo Scherer Perlin \\ Rua Washington Luiz, 855, 90010-460, Porto Alegre, RS, Brasil. E-mail: marcelo.perlin@ufrgs.br \\ Denis Borenstein \\ Rua Washington Luiz, 855, 90010-460, Porto Alegre, RS, Brasil. E-mail: denis.borenstein@ufrgs.br
}

